\title{
A W-Band Corrugated Output Horn and Window for Gyro-devices
}

\author{
Paul McElhinney, Craig R. Donaldson, Liang Zhang, Adrian W. Cross, Huabi Yin and Wenlong He \\ Department of Physics, SUPA, University of Strathclyde, Glasgow, Scotland, UK, G4 0NG
}

\begin{abstract}
A W-band corrugated horn incorporating a broadband vacuum window for use in a gyro-device as a quasioptical launcher has been designed, manufactured and experimentally measured. This horn, including a 3 disk vacuum window, converts a cylindrical $\mathrm{TE}_{11}$ mode into the free space TEM $_{00}$ mode over the frequency band of $90-100 \mathrm{GHz}$ with a reflection better than $-30 \mathrm{~dB}$ and a coupling efficiency of $\sim 99.4 \%$
\end{abstract}

\section{CORRUGATED LAUNCHER AND WINDOW}

A W-band gyrotron traveling wave amplifier (gyro-TWA) and gyrotron backward wave oscillator (gyro-BWO) [1] based on a cusp electron beam source [2-4] and a helically corrugated interaction region (HCIR) [5] have been developed to provide a continuously tunable source with a continuous wave (CW) power output of $\sim 5 \mathrm{~kW}$ and $\sim 10 \mathrm{~kW}$ respectively. The gyro-TWA was simulated to have a $3 \mathrm{~dB}$ frequency bandwidth of $90-100 \mathrm{GHz}$ while the gyro-BWO demonstrated a tuning range of $88-102.5 \mathrm{GHz}$ and has achieved an output power of $12 \mathrm{~kW} \mathrm{[6].} \mathrm{The} \mathrm{fundamental}$ operating mode in the gyro-TWA and BWO is an elliptically polarized $\mathrm{TE}_{11}$ mode. To provide a radiation source that is suitable for applications an output system must be implemented to convert the $\mathrm{TE}_{11}$ to a quasi-optical mode, which is preferable for coupling with external applications. One method of achieving this is by means of a corrugated mode converting horn [7]. This transforms the fundamental $\mathrm{TE}_{11}$ mode within the gyro-TWA to a hybrid mode that is generally accepted to consist of $85 \% \mathrm{TE}_{11}$ and $15 \% \mathrm{TM}_{11}$ (by power) and is closely coupled to the fundamental free space Gaussian mode $\left(\mathrm{TEM}_{00}\right)$ [8]. This Gaussian radiation beam is then free to pass through the vacuum window [9] unperturbed by the outer structure of the window with a very low reflection. Using this type of corrugated mode converting horn in favor of more conventional beam-wave decoupling methods can be advantageous due to the increase in performance that it makes possible. This method gives both a greater bandwidth and the capability to provide a source that is continuously tunable over this bandwidth. In designing the launcher system, including the window, the primary consideration was the reduction of the reflection. This is a critical parameter for the stable operation of the gyro-TWA, due to the possibility of stimulating unwanted oscillations by backward travelling waves. It was found that the optimal reflection was best achieved using a $\sin ^{2}$ profile [10] for the horn and by constructing a multi-layer vacuum window, which can effectively transmit the radiation over a large bandwidth. This initial profile, as well as the window structure, were optimized using a mode matching method and numerically validated by comparing the aperture fields with the fundamental Gaussian mode.

\section{EXPERIMENTAL RESULTS}

This horn was constructed by the electroforming of copper onto an aluminum substrate and the completed millimeter wave component was tested on a W-band Anritsu 3738A VNA. The reflection from the horn was determined by one port measurement where microwaves were radiated into free space. Far-field measurements of the horn showed that the -30 $\mathrm{dB}$ edge was within a half angle of 14.5 degrees and the pattern showed more than $99 \%$ of the output power was within 29 degrees. The simulated results demonstrated that the horn is coupled to the fundamental Gaussian with an efficiency of $\sim 99.4 \%$ and measured results show a reflection of better than $30 \mathrm{~dB}$.

\section{SUMMARY}

A high performance mode converting horn and window combination has been developed to produce a Gaussian output with a reflection over the $90-100 \mathrm{GHz}$ bandwidth of better than $-30 \mathrm{~dB}$. This second generation horn includes an output window, which allows for better integration with the gyrosystem and has a coupling between the $\mathrm{HE}_{11}$ mode and the free space Gaussian mode of $99.4 \%$ with the window.

Support for this work by the Science and Technology Facilities Council, UK is gratefully acknowledged. The authors thank the EPSRC, UK for providing the $\mathrm{PhD}$ studentship for P. McElhinney.

\section{REFERENCES}

[1] W. He, C. R. Donaldson, F. Li, L. Zhang, A. W. Cross, A. D. R. Phelps, K. Ronald, C. W. Robertson, C. G. Whyte, and A. R. Young, "W-band gyrodevices using helically corrugated waveguide and cusp gun: Design, simulation and experiment," TST, 4, pp. 9-19, 2011.

[2] W. He, C.G. Whyte, E.G. Rafferty, A.W. Cross, A.D.R. Phelps, K. Ronald, A.R. Young, C.W. Robertson, D.C. Speirs, and D.H. Rowlands, "Axis-encircling electron beam generation using a smooth magnetic cusp for gyrodevices," Appl. Phys. Lett. 93, 121501, 2008

[3] C.R. Donaldson, W. He, A.W. Cross, A.D.R. Phelps, F. Li, K. Ronald, C.W. Robertson, C.G Whyte, A.R. Young, Liang Zhang, "Design and numerical optimization of a cusp-based electron beam for millimetre-wave gyro-devices," IEEE Trans. Plasma Sci., 37, pp. 2153-2157, 2009.

[4] C. R. Donaldson, W. He, A.W. Cross, F. Li, A. D. R. Phelps, L. Zhang, K. Ronald, C. W. Robertson, C. G. Whyte, A. R. Young, "A cusp electron gun for millimeter wave gyro-devices", Appl. Phys. Lett., 96, 141501, 2010.

[5] L. Zhang, W. He, K. Ronald, A. D. R. Phelps, C. G. Whyte, C. W. Robertson, A. R. Young, C. R. Donaldson, and A. W. Cross, "Multi-mode coupling wave theory for helically corrugated waveguide," IEEE Trans. Microw. Theory Tech., 60, pp. 1-7, 2012

[6] W. He, C. R. Donaldson, L. Zhang, K. Ronald, P. McElhinney, A. W. Cross, "High power wideband gyrotron backward wave oscillator operating towards the terahertz region," Phys. Rev. Lett. 110, 165101, 2013.

[7] J.E. McKay, D.A. Robertson, P.A.S. Cruickshank, R.I.. Hunter, D.R. Bolton, R.J. Wylde, G.M. Smith, IEEE Trans. on Antennas and Propagation., 61, pp. 1714-1721, 2013.

[8] P. McElhinney, C.R. Donaldson, L. Zhang, and W. He, "A high directivity broadband corrugated horn for W-band gyro-devices," IEEE Trans. Antennas Propag. 61, pp. 1453-1456, 2013.

[9] C.R. Donaldson, W. He, L. Zhang, and A.W. Cross, "A W-band multilayer microwave window for pulsed operation of gyro-devices," IEEE Microw. Wireless Compon. Lett., 23, pp. 237-239, 2013.

[10] P. J. B. Clarricoats and A. D. Olver, Corrugated Horns for Microwave Antennas. Peregrinus, London, UK, 1984 